\title{
Quality improvement in neurology: Amyotrophic lateral sclerosis quality measures Report of the Quality Measurement and Reporting Subcommittee of the American Academy of Neurology
}

Robert G. Miller, MD

Benjamin Rix Brooks, MD

Rebecca J. Swain-Eng, MS

Robert C. Basner, MD

Gregory T. Carter, MD

Patricia Casey, OTR/L

Adam B. Cohen, MD

Richard Dubinsky, MD

Dallas Forshew, RN, BSN

Carlayne E. Jackson, MD

Ed Kasarskis, MD

Nicholas J. Procaccini, MD

Mohammed Sanjak, PhD, PT

Fredrik P. Tolin, MD, MBA

Correspondence to

American Academy of Neurology: quality@aan.com

Supplemental data at www.neurology.org
Amyotrophic lateral sclerosis (ALS) is a lethal, progressive neurodegenerative disease characterized by loss of motor neurons. ${ }^{1}$ Patients with ALS lose function in the limbs, speech, swallowing, and breathing muscles. The cause of the disease is still not known for most patients. Approximately 25,000 people in the United States have ALS, and 5,000 people are diagnosed with ALS annually in the United States. ${ }^{1}$ Most patients die from respiratory failure 2 to 5 years after onset of symptoms. Cognitive dysfunction is seen in $20 \%$ to $50 \%$ of patients. ${ }^{2}$ The disease burden for patients and caregivers is enormous. The average cost of care has been estimated at $\$ 50,000$ per patient per year. ${ }^{3}$

ALS is not curable, but a number of important therapies are now available. In 1999, the American Academy of Neurology (AAN) published an evidencebased practice parameter for managing patients with ALS, including recommendations for the only disease-modifying drug, riluzole, which modestly lengthens survival. ${ }^{4}$ That publication was updated in 2009 to include some important advances demonstrating the value of new treatment options such as multidisciplinary clinics, riluzole, noninvasive ventilation, enteral feeding, and symptomatic treatments for pseudobulbar affect and sialorrhea., ${ }^{5,6}$

The value of multidisciplinary clinics for persons with ALS has been demonstrated in several studies, showing longer survival, better quality of life, and greater access to therapies for patients with this disease. ${ }^{7-15}$ Moreover, the online outcomes project ALSConnection documented that patients attending multidisciplinary clinics were more satisfied with their medical care and the telling of the diagnosis and had more beneficial use of different therapies compared to those receiving community care. ${ }^{13}$ Enhanced survival and increased quality of life have been documented with utilization of noninvasive ventilation, ${ }^{5,7,16-18}$ and enteral feeding is probably effective in prolonging survival. $^{5}$

To identify gaps in care, specific aspects of management of patients with ALS have been evaluated serially using a national Amyotrophic Lateral Sclerosis Clinical Assessment, Research, and Education (ALS CARE) database to encourage compliance with evidence-based recommendations and to measure continuing quality improvement. ${ }^{14,19}$ The most recent analysis of 5,600 patients with ALS shows that proper management of many ALS symptoms has increased substantially since the first publication of the AAN ALS guidelines in 1999, and awareness of therapeutic opportunities has increased. However, many evidence-based treatment recommendations are still underutilized. ${ }^{14}$

These gaps in care led the AAN to develop a new ALS quality measurement set to improve the quality of care for patients with ALS. The AAN ALS quality measurement set was developed by an interdisciplinary expert panel work group representing physician organizations, patient advocacy groups, and other relevant stakeholder groups concerned about the care of patients with ALS. The AAN ALS quality measurement set includes measures that may be used in quality initiatives, public reporting (e.g., the Centers for Medicare \& Medicaid Services Physician Quality Reporting System), maintenance of certification performance in practice programs, and accountability programs. In addition, the quality measures may provide a matrix for achieving disease-specific care certification through The Joint Commission process for ALS-specific care certification. ${ }^{20}$

The AAN ALS quality measure set has value in improving care beyond that of traditional quality assessment methods. The AAN is an established measure developer. The AAN has produced quality

From the Forbes Norris MDA/ALS Research Center (R.G.M., D.F.), California Pacific Medical Center, San Francisco, CA; Carolinas Neuromuscular/ALS-MDA Center, Carolinas HealthCare System and Departments of Neurology (B.R.B., M.S.) and Kinesiology (M.S.), Carolinas Medical Center, University of North Carolina School of Medicine-Charlotte Campus, Charlotte, NC; American Academy of Neurology (R.J.S.-E.), Minneapolis, MN; Division of Pulmonary Medicine (R.C.B.), Columbia University College of Physicians and Surgeons, New York, NY; St. Luke's Rehabilitation Institute (G.T.C.), Spokane, WA; Department of Neurology (P.C.), Northwestern Medical Faculty Foundation, Chicago, IL; Massachusetts General Hospital and Harvard Medical School (A.B.C.), Boston, MA; Department of Neurology (R.D.), University of Kansas, Kansas City, KS; Department of Neurology (C.E.J.), University of Texas Health Science Center, San Antonio, TX; Department of Neurology (E.K.), University of Kentucky, Lexington, KY; Swedish Medical Center and University of Washington (N.J.P.), Seattle, WA; and Humana (F.P.T.), Chicago, IL.

Amyotrophic Lateral Sclerosis measurement set approved by the AAN Board of Directors on July 31, 2012.

Go to Neurology.org for full disclosures. Funding information and disclosures deemed relevant by the authors, if any, are provided at the end of the article. 
measures for stroke and stroke rehabilitation, ${ }^{21}$ Parkinson disease, ${ }^{22}$ and epilepsy. ${ }^{23}$ The details of the overall AAN measure development process are available, ${ }^{24}$ and additional details on the ALS measure development are available in the full manuscript and the full measurement set (appendices e- 1 and e- 2 on the Neurology ${ }^{\circledR}$ Web site at www.neurology.org).

METHODS The AAN ALS quality measure development process followed the AAN process for measure development. ${ }^{24}$ The steps in the measure development process require submitting the topic for selection, completing an evidence-based literature search, constructing draft measures and technical specifications, convening a multidisciplinary work group to draft candidate measures, soliciting public comments during a 30-day period, refining the final measures and corresponding technical specifications, and obtaining approvals from the AAN ALS quality measure expert panel work group, AAN committees, and the AAN Board of Directors. In addition, the measurement set was reviewed by the American Medical Association's Performance Measurement Advisory Group to assign Current Procedural Terminology (CPT)-II codes.

RESULTS The literature review and evidence search identified 378 recommendation statements from 20 guidelines and consensus papers ${ }^{5-7,16,18,25,26}$ and many supporting evidence papers (references in appendix $\mathrm{e}-1$ ). Review of the recommendation statements by the AAN ALS quality measure work group leadership resulted in 13 recommendation statements that were rated highest on clinical importance, link to desired outcomes, evidence base, level of evidence, gaps in care associated with the recommendation, and validity and feasibility to implement the recommendation in practice in a quality measure. Thirteen candidate measures were reviewed by the work group, and 2 measures were dropped at the face-to-face meeting on November 11, 2011 due to feasibility issues. The set of 11 measures was posted for a 30-day public comment period. A total of 222 comments were received from physicians, patients, insurers, and other interested stakeholders from the United States and Canada, which further refined the draft measures. The final 11 measures were approved by the AAN ALS quality measure work group, the AMA Performance Measurement Advisory Group for CPT-II codes, appropriate AAN committees, and lastly the AAN Board of Directors on July 31, 2012. This AAN ALS quality measurement set will be revised periodically with an extensive review every 3 years.

Brief measure titles and measure statements for each of the 11 ALS performance measures are listed in the table. The measurement set addresses accurate and appropriate evaluation/monitoring of disease status and associated symptoms to guide treatment options (measures 1, 3, 4, 5, 7, 8, and 9), effective therapeutic options in eligible patients (measures 2, 4, 6, and 8), increasing patient awareness of advanced planning (measure 10), and patient safety (measure 11). For the full measure specifications and exceptions, see appendix e-2. The measure statement contains the denominator and numerator for each measure. The appropriate exceptions for each measure can be found in the full measure specifications (appendix e-2).

DISCUSSION AAN ALS quality measures, derived from the best available evidence, may act as indicators of high-quality clinical care across the spectrum of neurologic, medical, and psychological domains inherent in the management of patients with ALS. The deployment of this AAN ALS quality measurement set culminates a progression from an individual formulation (Ten Commandments for Optimal Motor Neuron Disease Patient Care) ${ }^{27}$ through the demands for setting standards ${ }^{28}$ to addressing the gaps for quality standard-based clinical care. ${ }^{29}$ Attempts to evaluate the quality of care for patients with ALS have already commenced in France ${ }^{30}$ and the United Kingdom. ${ }^{31}$ The 11 AAN ALS quality measures described herein are intended to be implemented in clinical practice, including both individual and multidisciplinary practice environments, and are geared to facilitate quality improvement.

The AAN ALS quality measures were developed using the AAN's evidence-based measure development process utilized previously for stroke, parkinsonism, and epilepsy. ${ }^{24}$ Widespread adoption of the AAN ALS quality measures has the potential to substantially improve the quality of care for patients with ALS at all levels of health care delivery. Many patients receive some of their ALS care from primary care doctors who are likely to find many of the measures useful in improving the care they provide for patients with ALS. The AAN ALS quality measures may also identify the need for specialty care referrals for patients and improve overall care coordination. General neurologists, who may not regularly see many patients with ALS, may also improve the quality of care they deliver by following the ALS measures. Even ALS experts at multidisciplinary clinics, who see the majority of persons with ALS and should be wellversed with ALS quality improvement metrics and tactics, may improve the care they provide by uniformly applying all of these AAN ALS quality measures. In addition, by auditing patient medical records, clinicians will be able to demonstrate improvement in patient outcomes by following these AAN ALS quality measures. Data from clinicians in the field will provide additional support for implementing these measures in practice, public reporting programs, and other quality initiatives.

CONCLUSION The diagnosis of ALS has profound implications for the patient and his or her family. In a recent analysis, too few patients received evidence-based 
Measure title and description

1. ALS multidisciplinary care plan developed or updated

Percentage of patients diagnosed with ALS for whom a multidisciplinary care plan was developed, if not done previously, and the plan was updated at least once annually.

2. Disease-modifying pharmacotherapy for ALS discussed

Percentage of patients with a diagnosis of amyotrophic lateral sclerosis with whom the clinician discussed disease-modifying pharmacotherapy (riluzole) to slow ALS disease progression at least once annually.

\section{ALS cognitive and behavioral impairment screening}

Percentage of patients diagnosed with ALS who are screened at least once annually for cognitive impairment (e.g., frontotemporal dementia screening or ALS Cognitive Behavioral Screen [CBS]) and behavioral impairment (e.g., ALS CBS).

\section{ALS symptomatic therapy treatment offered}

Percentage of visits for patients with a diagnosis of ALS with patient offered treatment for pseudobulbar affect, sialorrhea, and ALS-related symptoms.

\section{ALS respiratory insufficiency querying and referral for pulmonary function testing}

Percentage of patients with a diagnosis of amyotrophic lateral sclerosis who were queried about symptoms of respiratory insufficiency (awake or associated with sleep) and referred for pulmonary function testing (e.g., vital capacity, maximum inspiratory pressure, sniff nasal pressure, or peak cough expiratory flow), at least every 3 months.

\section{ALS noninvasive ventilation treatment for respiratory insufficiency discussed}

Percentage of patients diagnosed with ALS and respiratory insufficiency with whom the clinician discussed at least once annually treatment options for noninvasive respiratory support (e.g., noninvasive ventilation, assisted cough).

7. ALS screening for dysphagia, weight loss, and impaired nutrition

Percentage of patients diagnosed with ALS who were screened at least every 3 months for dysphagia, weight loss, or impaired nutrition and the result(s) of the screening(s) was documented in the medical record.

\section{ALS nutritional support offered}

Percentage of patients diagnosed with ALS and dysphagia, weight loss, or impaired nutrition who were offered at least once annually dietary or enteral nutrition support via percutaneous endoscopic gastrostomy or radiographic inserted gastrostomy.

\section{ALS communication support referral}

Percentage of patients diagnosed with amyotrophic lateral sclerosis who are dysarthric who were offered a referral at least once annually to a speech-language pathologist for an augmentative/alternative communication evaluation.

\section{ALS end of life planning assistance}

Percentage of patients diagnosed with ALS who were offered at least once annually assistance in planning for end of life issues (e.g. advance directives, invasive ventilation, hospice).

\section{ALS falls querying}

Percentage of visits for patients with a diagnosis of amyotrophic lateral sclerosis with patient queried about falls within the past 12 months.

treatment that can ease the disease burden. Although incurable at this time, advances in contemporary care options available to the patient with ALS have been shown to prolong life and also to improve the quality of that life.

These AAN ALS quality measures have been developed to address gaps in patient care and to overcome the underutilization of evidence-based therapeutics for patients with ALS. The measures are concerned with supportive care, management of patient safety, and planning for complex care needs, using a patientcentered approach to proactive decision making. The AAN ALS quality measures encourage multidisciplinary care plans, treatments for respiratory and nutritional dysfunction, use of the single disease-modifying agent available, and plans for a smooth transition to palliative care. Multidisciplinary clinics are available to some patients, and, where available, referral is encouraged. The addition of practical and meaningful quality measures for the care of patients with ALS may raise the standard of care and lead to the desired outcome, an increased life expectancy with an enhanced quality of life.

\section{AUTHOR CONTRIBUTIONS}

Robert G. Miller: drafting/revising the manuscript, study concept or design, analysis or interpretation of data, accepts responsibility for conduct of research and will give final approval, study supervision, obtaining funding. Benjamin Rix Brooks: drafting/revising the manuscript, study concept or design, analysis or interpretation of data, accepts responsibility for conduct of research and will give final approval, acquisition of data, statistical analysis, study supervision. Rebecca J. Swain-Eng: drafting/ revising the manuscript, study concept or design, accepts responsibility for conduct of research and will give final approval, acquisition of data, study supervision. Robert C. Basner: drafting/revising the manuscript, study concept or design, accepts responsibility for conduct of research and will give final approval. Gregory T. Carter: drafting/revising the manuscript, study concept or design, analysis or interpretation of data, accepts responsibility for conduct of research and will give final approval, study supervision. Patricia Casey: drafting/revising the manuscript, accepts 
responsibility for conduct of research and will give final approval, acquistion of data. Adam B. Cohen: drafting/revising the manuscript, study concept or design, accepts responsibility for conduct of research and will give final approval, acquisition of data, study supervision. Richard $\mathrm{M}$ Dubinsky: drafting/revising the manuscript, study concept or design, analysis or interpretation of data, accepts responsibility for conduct of research and will give final approval. Dallas Forshew: drafting/revising the manuscript, accepts responsibility for conduct of research and will give final approval. Carlayne E. Jackson: drafting/revising the manuscript, accepts responsibility for conduct of research and will give final approval. Ed Kasarskis: drafting/revising the manuscript, analysis or interpretation of data, accepts responsibility for conduct of research and will give final approval. Nicholas J. Procaccini: drafting/revising the manuscript, accepts responsibility for conduct of research and will give final approval. Mohammed Sanjak: drafting/revising the manuscript, study concept or design, accepts responsibility for conduct of research and will give final approval. Fredrik P. Tolin: drafting/revising the manuscript, accepts responsibility for conduct of research and will give final approval.

\section{ACKNOWLEDGMENT}

The authors would like to thank all the ALS Measure Development Work Group members for their contributions and work that supported the development of this manuscript: Robert G. Miller, MD (neurology); Benjamin Rix Brooks, MD (neurology); Steven Ringel, MD (neurology); Hiroshi Mitsumoto, MD (neurology); Carlayne Jackson, MD (neurology); Christen Shoesmith, MD, BSc (neurology); Edward Kasarskis, MD, $\mathrm{PhD}$ (neurology); Robert C. Basner, MD (pulmonology); Nicholas Procaccini, MD (gastroenterology); Gregory Carter, MD (physical medicine and rehabilitation); Dallas Forshew, RN, BSN (nursing); Mohammed Sanjak, PhD, PT, MBA (physical therapy/occupational therapy); Pat Casey, MS, CRCC (physical therapy/occupational therapy); Bob Osborne, RN (hospice/palliative care); Valerie Cwik, MD (Muscular Dystrophy Association); Christine Jasch, OTR/L (patient representative); Fredrik Tolin, MD, MBA (Humana); Rebecca J. Swain-Eng, MS, CAE (AAN staff); Gina Gjorvad (AAN staff); Rebecca Kresowik (methodologist); Richard Dubinsky, MD (facilitator); Joel Kaufman, MD (facilitator); Adam Cohen, MD (facilitator); Christopher Bever, MD (AAN QMR); Eric Cheng, MD, MS (AAN QMR). The authors would also like to thank the Muscular Dystrophy Association for their support in the development of the measures.

\section{STUDY FUNDING}

No targeted funding reported.

\section{DISCLOSURE}

R. Miller has received research support from the Muscular Dystrophy Association and is a consultant for Cytokinetics and Asubio Pharmaceuticals. B. Brooks has received funding and/or research grants from AB Science, Acorda, ALS Therapy Alliance, Asubio, Avanir, Biogen Idec, Bristol-Myers Squibb, Cytokinetics, GlaxoSmithKline, Knopp Bioscience, Muscular Dystrophy Association, Neuraltus, National Institute of Neurological Disorders and Stroke Clinical Research Consortium, QuestCor, and Teva. R. Swain-Eng is a full-time employee of the American Academy of Neurology. R. Basner is principal investigator of a Muscular Dystrophy Association grant, Opto-Electronic Plethysmography (OEP): A novel non-invasive quantitative assessment of lower rib cage paradox and use of accessory muscles in patients with amyotrophic lateral sclerosis; Site Investigator and Sleep Protocol Subcommittee member of an NHLBI/NIH grant, Sleep-Disordered Breathing During Pregnancy and Risks to Cardiovascular Health; and coinvestigator of the following R01HL103676-01A1 NIH/NHLBI, Subclinical Interstitial Lung Disease in MESA; R01HL093081 NIH/NHLBI, Pulmonary Vascular Changes in Early COPD; and InterMune PIPF-016, a randomized, double-blind, placebo-controlled, phase 3 study of the efficacy and safety of Pirfenidone in patients with Idiopathic Pulmonary Fibrosis (IPF). G. Carter reports no disclosures. P. Casey is a full-time employee of Northwestern Medical Faculty Foundation, Department of Neurology. A. Cohen reports no disclosures. R. Dubinsky reports disclosures for relationships with Allergan Pharmaceuticals, NIH, and AHRQ. D. Forshew is a consultant for Questcor and Asubio Pharmaceuticals. C. Jackson has received research support from Knopp
Pharmaceuticals, Biogen Idec, and Cytokinetics. E. Kasarskis is a consultant for Asubio Pharmaceuticals and ATSDR. N. Procaccini reports no disclosures. M. Sanjak reports no disclosures. F. Tolin reports no disclosures. Go to Neurology.org for full disclosures.

Received June 17, 2013. Accepted in final form August 13, 2013.

\section{REFERENCES}

1. National Institute of Neurological Disorders and Stroke. Amyotrophic lateral sclerosis fact sheet. Available at: http:// www.ninds.nih.gov/disorders/amyotrophiclateralsclerosis/ detail_ALS.htm. Accessed February 6, 2012.

2. Woolley SC. Utility of the ALS cognitive behavioral Screen. Neurodegen Dis Manage 2011;1:473-479.

3. Schepelmann K, Winter Y, Spottke A, et al. Socioeconomic burden of amyotrophic lateral sclerosis, myasthenia gravis and facioscapulohumeral muscular dystrophy. J Neurol 2010;257:14-23.

4. Miller RG, Rosenberg JA, Gelinas DF, et al; ALS Practice Parameters Task Force. Practice parameter: the care of the patient with amyotrophic lateral sclerosis (an evidencebased review): report of the Quality Standards Subcommittee of the American Academy of Neurology. Neurology 1999;52:1311-1323.

5. Miller RG, Jackson CE, Kasarskis EJ, et al. Practice parameter update: the care of the patient with amyotrophic lateral sclerosis: drug, nutritional, and respiratory therapies (an evidence-based review): report of the Quality Standards Subcommittee of the American Academy of Neurology. Neurology 2009;73:1218-1226.

6. Miller RG, Jackson CE, Kasarskis EJ, et al. Practice parameter update: the care of the patient with amyotrophic lateral sclerosis: multidisciplinary care, symptom management, and cognitive/behavioral impairment (an evidence-based review): report of the Quality Standards Subcommittee of the American Academy of Neurology Neurology 2009:73: 1227-1233.

7. EFNS Task Force on Diagnosis and Management of Amyotrophic Lateral Sclerosis; Andersen PM, Abrahams S, Borasio GD, et al. EFNS guidelines on the clinical management of amyotrophic lateral sclerosis (MALS) — revised report of an EFNS task force. Eur J Neurol 2012;19: 360-375.

8. Chio A, Bottacchi E, Buffa C, Mutani R, Mora G. Positive effects of tertiary centres for amyotrophic lateral sclerosis on outcome and use of hospital facilities. J Neurol Neurosurg Psychiatry 2006;77:948-950.

9. Traynor BJ, Alexander M, Corr B, et al. Effects of a multidisciplinary ALS clinic on survival. J Neurol Neurosurg Psychiatry 2003;74:1258-1261.

10. Van den Berg JP, Kalmijn S, Lindeman E, et al. Multidisciplinary ALS care improves quality of life in patients with ALS. Neurology 2005;65:12641267.

11. Aridegbe T, Kandler R, Walters SJ, Walsh T, Shaw PJ, McDermott CJ. The natural history of motor neuron disease: assessing the impact of specialist care. Amyotroph Lateral Scler 2013;14:13-19.

12. Rodriguez de River FJ, Oreja Guevara C, San Gallegal I, et al. Outcome of patients with amyotrophic lateral sclerosis attending in a multidisciplinary care unit. Neurologia 2011;26:455-460.

13. Miller RG, Scholtz D, Spitalny GM, et al. Outcomes of patients with ALS in the community, new insights from 
the web-based ALS patient care database. Amyotroph Lateral Scler 2006;7:56-57.

14. Miller RG, Anderson F, Brooks BR, et al. ALS CARE Study Group. Outcomes research in amyotrophic lateral sclerosis: lessons learned from the amyotrophic lateral sclerosis clinical assessment, research, and education database. Ann Neurol 2009;65:S24-S28.

15. Riemenschneider K, Forshew D, Miller RG. Multidisciplinary clinics: optimizing treatment for patients with amyotrophic lateral sclerosis. Neurodegen Dis Manage 2013;3:157-167.

16. National Institute for Health and Clinical Excellence (NICE). Non-invasive ventilation for motor neurone disease. Available at: http://guidance.nice.org.uk/nicemedia/ live/13057/49885/49885.pdf. Accessed October 4, 2011.

17. Bourke SC, Tomlinson M, Williams TL, et al. Effects of non-invasive ventilation on survival and quality of life in patients with amyotrophic lateral sclerosis: a randomised controlled trial. Lancet Neurol 2006;5:140-147.

18. Heffernan C, Jenkinson C, Holmes T, et al., Management of respiration in MND/ALS patients: an evidence based review. Amyotroph Lateral Scler 2006;7:5-15.

19. Bradley WG, Anderson F, Gowda N, Miller RG. Changes in the management of ALS since the publication of the AAN ALS practice parameter 1999. Amyotroph Lateral Scler Other Motor Neuron Disord 2004;5:240-244.

20. Williams NM, Bravver EK, Bockenek WL, et al. The Joint Commission (TJC) disease-specific care certification (DSC) program for amyotrophic lateral sclerosis (ALS) - a structured mechanism developed for performance measure Implementation, audit, and compliance assessment allowing evolution from process—-based to patient—outcome—-based improvements in an ALS multidisciplinary center available internationally. Amyotroph Lateral Scler 2012;13:40.

21. American Academy of Neurology, American College of Radiology, National Committee for Quality Assurance, American Medical Association-convened Physician Consortium for Performance Improvement. Stroke and stroke rehabilitation performance measurement set. 2012. Available at: www.ama-assn.org/ama1/pub/upload/mm/pcpi/ stroke-worksheets.pdf. Accessed October 31, 2013.

22. Cheng EM, Tonn S, Swain-Eng R, et al; for the American Academy of Neurology Parkinson Disease Measure Devel- opment Panel. Quality improvement in neurology: AAN Parkinson disease quality measures. Neurology 2010;75: 2021-2027.

23. Fountain NB, Van Ness PC, Swain-Eng R, Tonn S, Bever CT Jr. Quality improvement in neurology: AAN epilepsy quality measures: report of the Quality Measurement and Reporting Subcommittee of the American Academy of Neurology. Neurology 2011;76:94-99.

24. Bever CT, Dubinsky R, Tonn S, Swain-Eng R; for the Quality Measures and Reporting Subcommittee. Quality measure development process manual, 2010 edition. Available at: www.aan.com/practice/quality-measures/aboutquality-measures. Accessed October 31, 2013.

25. Miller RG, Mitchell JD, Moore DH. Riluzole for amyotrophic lateral sclerosis (ALS)/motor neuron disease (MND). Cochrane Database of Systematic Reviews 2012, Issue 3. Art. No.: CD001447. doi: 10.1002/14651858.CD001447. pub3.

26. National Institute for Health and Clinical Excellence (NICE). Guidance on the use of riluzole (rilutek) for the treatment of motor neuron disease. Available at: guidance.nice.org.uk/ nicemedia/live/11415/32139/32139.pdf. Accessed October 31, 2013.

27. Norris F. The "Ten Commandments" for optimal motor neuron disease patient care. Available at: http://www.cpmc. org/services/als/about/als_ten.html. Accessed October 31, 2013.

28. Hardiman O, Traynor BJ, Corr B, Frost E. Models of care for motor neuron disease: setting standards. Amyotroph Lateral Scler Other Motor Neuron Disord 2002;3:182-185.

29. Radunović A, Mitsumoto H, Leigh PN. Clinical care of patients with amyotrophic lateral sclerosis. Lancet Neurol 2007;6:913-925.

30. Corcia P, Bourdillon F. Evaluation of the national reference center for support of amyotrophic lateral sclerosis (ALS) in Paris on Société Francaise de Santé Publique [French Society of Public Health]. 2008. Available at: http://www.sfsp.fr/activites/file/rapportSLA.pdf. Accessed October 31, 2013.

31. National Institute for Health and Clinical Excellence. NICE quality standards and clinical audit. Available at: http://www. nice.org.uk/media/835/EC/NICEQualityStandardsAndAudit. pdf.

This is a co-publication of Neurology (American Academy of Neurology), Muscle \& Nerve (American Academy of Neuromuscular and Electrodiagnostic Medicine) and ALS and Frontotemporal Degeneration Journal. An edited version for an international audience will be published in ALS and Frontotemporal Degeneration Journal. 


\section{Neurology}

Quality improvement in neurology: Amyotrophic lateral sclerosis quality measures: Report of the Quality Measurement and Reporting Subcommittee of the American Academy of Neurology

Robert G. Miller, Benjamin Rix Brooks, Rebecca J. Swain-Eng, et al. Neurology 2013;81;2136-2140 Published Online before print November 22, 2013

DOI 10.1212/01.wnl.0000437305.37850.f9

This information is current as of November 22, 2013

\section{Updated Information \&} Services

Supplementary Material

\section{References}

\section{Citations}

Subspecialty Collections

Permissions \& Licensing

Reprints including high resolution figures, can be found at: http://n.neurology.org/content/81/24/2136.full

Supplementary material can be found at: http://n.neurology.org/content/suppl/2013/11/22/01.wnl.0000437305.3 7850.f9.DC1

This article cites 22 articles, 8 of which you can access for free at: http://n.neurology.org/content/81/24/2136.full\#ref-list-1

This article has been cited by 6 HighWire-hosted articles: http://n.neurology.org/content/81/24/2136.full\#\#otherarticles

This article, along with others on similar topics, appears in the following collection(s):

\section{All Education}

http://n.neurology.org/cgi/collection/all_education

All Practice Management

http://n.neurology.org/cgi/collection/all_practice_management Amyotrophic lateral sclerosis

http://n.neurology.org/cgi/collection/amyotrophic_lateral_sclerosis_

Information about reproducing this article in parts (figures,tables) or in its entirety can be found online at:

http://www.neurology.org/about/about_the_journal\#permissions

Information about ordering reprints can be found online:

http://n.neurology.org/subscribers/advertise

Neurology ${ }^{\circledR}$ is the official journal of the American Academy of Neurology. Published continuously since 1951 , it is now a weekly with 48 issues per year. Copyright (C) 2013 American Academy of Neurology. All rights reserved. Print ISSN: 0028-3878. Online ISSN: 1526-632X.

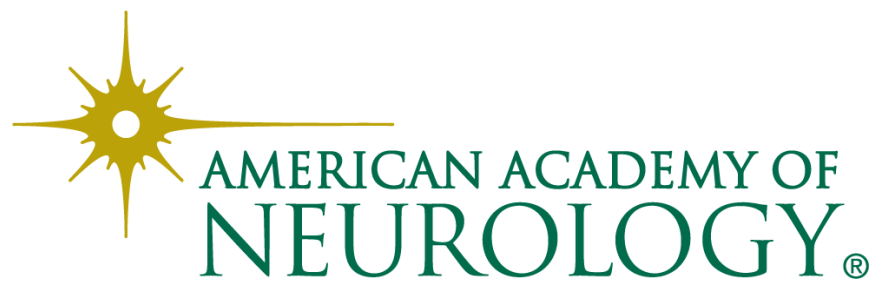

